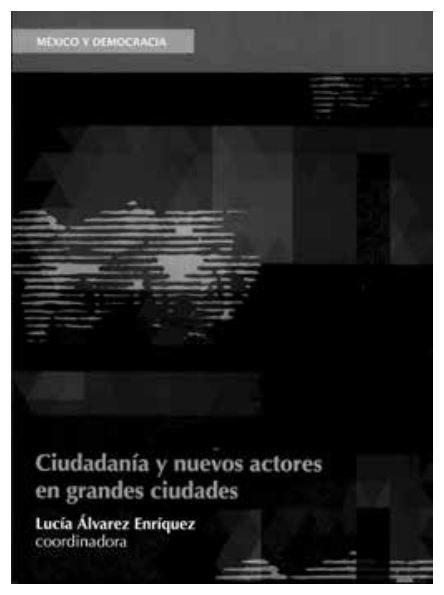

- Ciudadanía y nuevos actores

en grandes ciudades

Lucía Álvarez Enríquez (COORD.),

2016

Centro de Investigaciones

Interdisciplinarias en Ciencias

y Humanidades-Universidad

Nacional Autónoma de México/

Universidad Autónoma Metropolitana/

Juan Pablos, México

\section{Ciudadanía en las selvas urbanas}

\author{
ALBERTO AZIZ NASSIF
}

Citizenship in the Urban Jungles

\section{¿Cómo nos organizamos?}

ALBERTO AZIZ NASSIF

Centro de Investigaciones y Estudios Superiores

en Antropología Social-Ciudad de México,

Ciudad de México, México

aziz@ciesas.edu.mx

Desacatos 55 ,

septiembre-diciembre 2017, pp. 192-195
La coordinadora del libro comienza con una serie de preguntas sobre la ciudad global, el Estado, los actores, los procesos de construcción de ciudadanía, los derechos, los procesos urbanos, los proyectos. Además, propone una estructura en seis partes, en la que los capítulos, o la mayoría, encuentra su lógica de ubicación y lectura: mercado inmobiliario, innovación social, distribución de recursos y bienes urbanos, construcción de ciudadanía en ciudades neoliberales, espacios ciudadanos y discursos sobre ciudadanía. 


\section{¿Desde dónde presentar el libro?}

La lectura resultó una experiencia de varias mixturas. He trabajado el problema de la ciudadanía, pero desconozco el de la ciudad y los estudios urbanos. Este conocimiento/desconocimiento me obligó a leer con cuidado y ver que lo que puede resultar familiar y obvio para algunos especialistas, para mí es un territorio nuevo, con autores, mapas y geografías extrañas, por eso mi lectura se hizo desde ese espacio de comprensión.

\section{¿Qué me llamó la atención de forma particular?}

Lo que vi fue una serie de conexiones y vinculaciones que tal vez no son explícitas ante la mirada de los autores y la coordinadora, pero que están ahí para un lector externo: la visión de cómo la ciudad, en particular la Ciudad de México, se ha transformado para llegar a ser una megalópolis en la que el proyecto mercantil, neoliberal, ha ganado la partida y lo que predomina son los intereses económicos de grandes consorcios, frente a luchas desarticuladas y proyectos que defienden otras visiones de la ciudad y de lo público, pero que son subalternas. Quedan las historias del bando 2, las normas generales de ordenación 30 y 31, las Zonas de Desarrollo Económico y Social (Zodes) y todo el armazón que dio cuerpo a un modelo hegemónico. ${ }^{1}$ Encontré que muchas expresiones y adjetivos se repiten en estas historias: ciudad fragmentada, ciudad mercantilizada, ciudad globalizada...

Así, podemos ir de las burbujas inmobiliarias al uso del agua, la infraestructura o las luchas de vecinos. En suma, hay múltiples entrecruzamientos entre los textos de Patricia Ramírez Kuri y Carlos San Juan Victoria, como entre los trabajos de Sergio Tamayo y María Cristina Sánchez-Mejorada, y entre Lucía Álvarez Enríquez y Alejandra Leal Martínez.
De la misma forma, podemos ir de la Ciudad de México a Bogotá, São Paulo o Buenos Aires. Nos quedan dimensiones urbanas, actores y procesos de ciudadanía. El fenómeno urbano, la cuestión urbana, como la llamó en la década de 1970 Manuel Castells (1974), es un mundo que abarca la multidimensionalidad en la que se ubican los objetos de estudio de este libro.

El sujeto es la ciudad y sus vínculos diversos con la ciudadanía. Los dos conceptos centrales dan paso a una serie de enfoques y acercamientos para ver cómo sucede el fenómeno urbano.

Me llamó la atención que en una buena cantidad de capítulos hay clasificaciones que se componen de tres contenidos para ver derechos, modelos, proyectos, etc., y que en la mayoría de los trabajos - ochoel campo de investigación es la Ciudad de México, un laboratorio complicado que permite ensayar y experimentar con varias hipótesis, poner a prueba y comparar con otras ciudades, sólo de manera tangencial. Ya sea toda la ciudad, unas delegaciones, unas dimensiones, algunos referentes, pero la Ciudad de México es el gran sujeto del libro.

El bando 2, vigente de 2001 a 2007, buscaba revertir el crecimiento desordenado de la ciudad, preservar el suelo de conservación de la capital, impedir que la mancha urbana siguiera creciendo hacia las zonas de recarga de mantos acuíferos, en las que se produce la mayor parte del oxígeno para la ciudad, y construir vivienda para la población pobre en las delegaciones del centro, Cuauhtémoc, Benito Juárez, Miguel Hidalgo y Venustiano Carranza. Las normas generales de ordenación 30 y 31, discutidas en la Asamblea Legislativa del Distrito Federal en 2014, fijaban topes en los precios de venta de vivienda de interés social y residencial, respectivamente. El proyecto de las Zodes, lanzado en 2013, proponía la reestructuración de varias zonas de la ciudad para generar "ciudades" con actividades específicas y delimitadas, como la Ciudad de la Salud, la Ciudad Administrativa, el Corredor Cultural Chapultepec, la Ciudad Agroindustrial y la Ciudad del Futuro. 


\section{¿Qué me gustaría destacar de los textos?}

Propongo, de forma casi telegráfica, una idea para cada texto:

El proceso de 15 años en el que se crea el modelo hegemónico de urbanización de la Ciudad de México. La burbuja inmobiliaria y los megaproyectos, todo bajo la gobernanza de la izquierda, de un partido supuestamente de izquierda, que por sus resultados poco tendría que ver con el triunfo de ese modelo, como lo estudia Carlos San Juan Victoria. ¿Simulación política frente a las fuerzas del mercado?

En Europa, se mira la innovación social desde la perspectiva de dos grandes paradigmas que están en controversia: la lectura neoliberal, como el traslado de responsabilidades del Estado a los gobiernos locales, o las lecturas más sociales de la innovación, que apuntan hacia una creación de valor social, como lo hacen los movimientos sociales, las propuestas socializadoras, la producción cooperativa, la centralidad del problema de vivienda "como núcleo básico de ciudadanía”, la autoorganización y la autonomía, experiencias que hoy se viven en España y que Joan Subirats apunta con la experiencia de los fenómenos que dejó el 15 $\mathrm{M}^{2}$ y los nuevos gobiernos locales en Madrid y Barcelona.

El seguimiento de las experiencias de participación ciudadana y su institucionalización en Bogotá, donde varios alcaldes con una visión original lograron darle la vuelta a varias inercias destructivas. Fabio E. Velásquez se pregunta cómo acabar con el maniqueísmo entre participación e institucionalización. Es un poco lo que pasa con el falso problema entre democracia representativa y participativa.

Metabolismo y ecología política sobre el agua es el tema de un capítulo que expone los problemas que conlleva la privatización y mercantilización del agua, frente a un paradigma que considera el agua un derecho humano, que necesita una "genuina gestión ciudadana”, como anota Gian Carlo Delgado Ramos.
Llegamos a la cultura y la ciudad, como espacio para el desarrollo de las infraestructuras del sentido y los derechos de nueva generación. El mundo de la creatividad ciudadana. ¿Qué sería de nuestras ciudades sin esa parte? Es lo que hace diferente a una población de una ciudad. Es donde están las marcas del carácter, el atractivo y la singularidad del ser de la ciudad. Es lo que civiliza, porque frente a esos territorios de la ley de la selva que son nuestras ciudades, están los territorios de cultura para la equidad, como dice Ana Rosas Mantecón. Por eso termina su texto con una cita de Jérôme Monnet que define la urbanidad como "el arte de vivir juntos mediado por la ciudad” (p. 154).

Aparecen las contradicciones del espacio público, porque es un espacio de la ciudadanía. Regresamos al modelo que ha hecho de esta ciudad la selva de intereses, pero no por arte de magia, sino por las estrategias del gobierno, como la flexibilización del uso de suelo, la transferencia de potencial - las grandes inversiones - y las zonas especiales de desarrollo. Por eso vienen la desigualdad y la fragmentación, por eso se vulneran los derechos ciudadanos y afloran las contradicciones entre lo local y lo metropolitano, entre el discurso y la política urbana, y entre el mercado y las comunidades, señala Patricia Ramírez Kuri. Al final, parece que nos quedamos con buenos análisis, deseos de lo público, pero el modelo mercantil avanza incontenible.

Entramos a Brasil. Los movimientos por el pase libre y los comités populares de la copa llevan a

El Movimiento 15M, también llamado "de los indignados", es una movilización ciudadana que surgió después de las manifestaciones pacíficas del 15 de mayo de 2011 en varias ciudades de España. El 15M demanda al gobierno cambios en la Ley Electoral, atención a derechos básicos, como salud y vivienda, reformas fiscales que beneficien a los ciudadanos, y nacionalización de entidades bancarias rescatadas por el Estado, entre otras propuestas plasmadas en su texto programático del 20 de mayo de 2011. 
Monika Dowbor y José Szwako al análisis tillyano de los repertorios de acciones y movimientos. ¿Qué pensar ahora de los movimientos de 2013, cuando el país se encamina a una neoliberalización y con una democracia representativa en crisis?

El derecho a la ciudad, sus actores y movimientos, su sentido y sus luchas; la historia de la política urbana actual, con "la actitud de los gobernantes y los mecanismos de gestión que vulneran los derechos de la mayoría a una vida, digna, equitativa, justa y democrática” (p. 229), escribe María Cristina Sánchez-Mejorada en su capítulo, que concluye con una larga cita de los Vecinos Unidos de Coyoacán, que denuncian los megaproyectos, los parquímetros, el excesivo impuesto predial, el urbanicidio, etcétera.

El acceso a los bienes urbanos y el famoso movimiento urbano popular hacen frente a esta ciudad que se ha desdoblado al extremo y al que se califica de insular, de archipiélago, de estar fragmentada. Los grupos populares se han hecho un espacio mediante invasiones, fraccionamiento ilegal y gestiones bajo presión, como relata Lucía Álvarez Enríquez. Aquí están los testimonios del Movimiento Urbano Popular mediante la etnografía, queda el registro de las experiencias y las voces, las dificultades para hacer permanente algo que es efímero en el oriente de la ciudad.

¿Qué es eso del espacio ciudadano?, se pregunta Sergio Tamayo para comenzar su análisis (p. 280). La ciudad como una construcción social, soportada por una materialidad visible y palpable. La ciudad tocada y modelada por el modelo neoliberal, la acumulación por desposesión, como dice Harvey
(2005). La ciudadanía, pareja teórica y práctica de la urbe. La ciudadanía como un sistema en conflicto, en movimiento, y el espacio ciudadano como resultado de luchas, objetivas y subjetivas, autónomos y en constante movimiento. Estos espacios se definen por la disputa entre proyectos. Tamayo señala cuatro: corporativo, privatizador, de centro-izquierda y el de una sociedad civil anticapitalista.

Vamos a Buenos Aires para ver la diferencia entre los "solventes" de clase media y los populares “insolventes”, como escriben Pedro Pírez y Natalia Cosacov. Seguimos con las trabajadoras sexuales callejeras en la Ciudad de México, de las que Marta Lamas afirma: "estas trabajadoras se han convertido en sujetos políticos que reclaman una ciudadanía igualitaria” (p. 328). Terminamos con la relación antagónica que se construye entre la informalidad y la ciudadanía, como lo trabaja Alejandra María Leal Martínez.

Todo lo que usted quiso saber sobre la ciudad y los ciudadanos, y siempre tuvo duda de preguntar, está aquí, en Ciudadanía y nuevos actores en grandes ciudades. Es un libro que recomiendo, que puede tener múltiples lecturas y consultas. El texto será referencia y es nudo de múltiples proyectos de investigación, me atrevo a decir, la mayoría en proceso, inacabados, porque se trabaja por etapas, por hipótesis temporales, porque siempre descubrimos algo que pensamos que es original, aunque al día siguiente lo desechemos. Termino con una idea que me queda, de cuál sería un título alternativo para este libro: grandes ciudades, proyectos neoliberales, espacios fragmentados y pequeñas ciudadanías. D

\section{Bibliografía}

Castells, Manuel, 1974, La cuestión urbana, Siglo XXI Editores, México.

Harvey, David, 2005, El “nuevo" imperialismo: acumulación por desposesión, Consejo Latinoamercano de Ciencias Sociales, Buenos Aires. 